\title{
Junctophilin 3 expresses in pancreatic beta cells and is required for glucose-stimulated insulin secretion
}

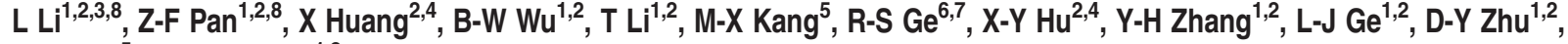 \\ Y-L Wu*,5 and Y-J Lou, ${ }^{*, 1,2}$
}

It is well accepted that junctophilin (JPHs) isoforms act as a physical bridge linking plasma membrane and endoplasmic reticulum (ER) for channel crosstalk in excitable cells. Our purpose is to investigate whether JPHs are involved in the proper communication between $\mathrm{Ca}^{2+}$ influx and subsequent $\mathrm{Ca}^{2+}$ amplification in pancreatic beta cells, thereby participating in regulating insulin secretion. The expression of JPH isoforms was examined in human and mouse pancreatic tissues, and JPH3 expression was found in both the beta cells. In mice, knockdown of Jph3 (si-Jph3) in islets decreased glucose-stimulated insulin secretion (GSIS) accompanied by mitochondrial function impairment. Si-Jph3 lowered the insulin secretory response to $\mathrm{Ca}^{2+}$ signaling in the presence of glucose, and reduced $\left[\mathrm{Ca}^{2+}\right]_{c}$ transient amplitude triggered by caffeine. Si-Jph3 also attenuated mitofusin 2 expression, thereby disturbing the spatial organization of ER-mitochondria contact in islets. These results suggest that the regulation of GSIS by the $\mathrm{K}_{\mathrm{ATP}}$ channel-independent pathways is partly impaired due to decrease of JPH3 expression in mouse islets. JPH3 also binds to type 2 ryanodine receptors (RyR2) in mouse and human pancreatic tissues, which might contribute to $\mathrm{Ca}^{2+}$ release amplification in GSIS. This study demonstrates some previously unrecognized findings in pancreatic tissues: (1) JPH3 expresses in mouse and human beta cells; (2) si-Jph3 in mouse primary islets impairs GSIS in vitro; (3) impairment in GSIS in si-Jph3 islets is due to changes in RyR2-[Ca $\left.{ }^{2+}\right]_{\mathrm{c}}$ transient amplitude and ER-mitochondria contact.

Cell Death and Disease (2016) 7, e2275; doi:10.1038/cddis.2016.179; published online 23 June 2016

Insulin secretion is associated with alterations of intracellular glucose metabolism, electrical excitability and $\mathrm{Ca}^{2+}$ handling of pancreatic beta cells. ${ }^{1-6}$ In addition to association with $\mathrm{Ca}^{2+}$ release from type 2 ryanodine receptors (RyR2), insulin secretion from pancreatic beta cells is caused by glucosestimulated [ATP] increase, $\mathrm{Ca}^{2+}$ entry via voltage-gated $\mathrm{Ca}^{2+}$ channels (VGCC) in plasma membrane (PM)..$^{7-12}$ The resultant rise in intracellular $\mathrm{Ca}^{2+}$ concentration depends on the organization of VGCC and RyR2 within junctional membrane complexes (JMCs) in excitable cells, ${ }^{13,14}$ but how the proper communication of $\mathrm{Ca}^{2+}$ influx and subsequent $\mathrm{Ca}^{2+}$ amplification influences the insulin secretion is not fully elucidated. Glucose-stimulated insulin secretion (GSIS) is the principal mechanism of insulin secretion. Loss or reduced GSIS are characteristic features of type 2 diabetes mellitus. ${ }^{9}$ The mechanism involved in triggering GSIS is well accepted as the $\mathrm{K}_{\text {ATP }}$ channel-dependent and -independent pathways, ${ }^{6,9}$ the mitochondrial metabolism is the essential upstream core shared by both the pathways. However, to date, the link between $\mathrm{Ca}^{2+}$ amplification handling and ATP production during GSIS is not fully understood.

The family of junctophilin (JPHs) isoforms serves as a physical bridge and effectively contributes to the formation of JMCs for ion channel functional crosstalk in excitable cells. ${ }^{15,16}$ Although pancreatic beta cells are electrically excitable, ${ }^{6}$ the role of $\mathrm{JPHs}$ in insulin release remains so far undefined. RyR2, inositol 1,4,5-trisphosphate receptor (IP3R) and sarco-endoplasmic reticulum $\mathrm{Ca}^{2+}$-ATPase $2 \mathrm{~b}$ and 3 (SERCA2b, 3) in endoplasmic reticulum (ER) are closely associated with insulin release. ${ }^{1,3,4,17,18}$ Given that $\mathrm{Ca}^{2+}$ release amplification depends on the organization of VGCC and RyR2 within JMCs, whether the impairment of JMCs affects insulin secretion in beta cells should be urgently clarified. Knockout mice lacking the JPH isoforms display related pathological phenotypes, ${ }^{15,16,19-22}$ indicating that JPHs are essential for the physiological communication.

\footnotetext{
${ }^{1}$ Insititute of Pharmacology and Toxicology, College of Pharmaceutical Sciences, Zhejiang University, Hangzhou 310058, China; ${ }^{2}$ Key Innovation Team for Stem Cell Translational Medicine of Cardiovascular Disease of Zhejiang Province, College of Pharmaceutical Sciences, Zhejiang University, Hangzhou 310058, China; ${ }^{3}$ Department of Pharmacy, The First Affiliated Hospital, College of Medicine, Zhejiang University, Hangzhou 310003, Zhejiang, China; ${ }^{4}$ Cardiovascular Key Laboratory of Zhejiang Province, The 2nd Affiliated Hospital, College of Medicine, Zhejiang University, Hangzhou 310009, China; ${ }^{5}$ Department of General Surgery, The 2nd Affiliated Hospital, College of Medicine, Zhejiang University, Hangzhou 310009, China; ${ }^{6}$ The Population Council at the Rockefeller University, New York 10021, NY, USA and ${ }^{7}$ Institute of Reproductive Biomedicine, the 2nd Affiliated Hospital, Wenzhou Medical University, Wenzhou 325027, China

*Corresponding author: Y-L Wu or Y-J Lou, Institute of Pharmacology, Toxicology and Biochemical Pharmaceutics, College of Pharmaceutical Sciences, Zhejiang University, 866 Yuhangtang Road, Hangzhou, Zhejiang Province, P. R. China. Tel: +86-571-88208403; Fax: 86-571-88208402; E-mail: yulianwu2003@yahoo.ca or yijialou@ zju.edu.cn ${ }^{8}$ These two authors contributed equally to this work.

Abbreviations: Bax, Bcl2-associated X protein; Bcl-2, B cell leukemia/lymphoma 2; $\left[\mathrm{Ca}^{2+}\right]_{\mathrm{C}}$, cytoplasmic matrix $\mathrm{Ca}^{2+}$; $\left[\mathrm{Ca}^{2+}\right]_{\mathrm{m}}$, mitochondrial matrix $\mathrm{Ca}^{2+}$; $\mathrm{CPA}$, cyclopiazonic acid; elF2 $\alpha$, eukaryotic initiation factor $2 \alpha$; ER, endoplasmic reticulum; Err $\alpha$, estrogen-related receptor $\alpha$; GRP78, glucose-regulated protein 78; GRP94, glucose-regulated protein 94; GSIS, glucose-stimulated insulin secretion; IP3, D-myo-inositol 1,4,5-trisphosphate; IP3R, inositol 1,4,5-trisphosphate receptor; JMCs, junctional membrane complexes; JPH3, junctophilin 3; LTCC, L-type calcium channel; Mfn, mitofusin; Orai1, ORAI calcium release-activated calcium modulator 1; PGC-1 $\alpha$, peroxisome proliferator-activated receptor $\gamma$ coactivator-1 $\alpha$; PM, plasma membrane; PPAR $\beta$, peroxisome proliferator-activated receptor $\beta$; RyR, ryanodine receptor; SERCA, sarco-endoplasmic reticulum $\mathrm{Ca}^{2+}$-ATPase; Sp1, specificity protein 1; STIM1, stromal interaction molecule 1; VGCC, voltage-gated Ca ${ }^{2+}$ channels; $\Delta \Psi \mathrm{Im}$, mitochondrial membrane potential
}

Received 10.3.16; revised 26.5.16; accepted 30.5.16; Edited by M Agostini 
In vivo deletion of $R y R 2$ reduces $\mathrm{Ca}^{2+}$, ATP and oxidative metabolism, thereby leading to metabolic reprogramming and cell death. ${ }^{23}$ Furthermore, sleep deprivation upregulates Jph3 transcription in mouse brain via stressful conditions through RyR-mediated intracellular calcium mobilization, ${ }^{24}$ suggesting that Jph3 might also be a functional gene under stress in addition to its structural contribution. Given that $\mathrm{Ca}^{2+}$ signaling in GSIS includes the amplifying features through $\mathrm{K}_{\mathrm{ATP}^{-}}$ independent pathway, ${ }^{6,9,25,26}$ JPHs probably contribute to maintaining mitochondria function in beta cells. Importantly, the relationships between abnormal JPH isoforms and human diseases have also been confirmed. JPH2 deficiency resulted in hypertrophied and failing myocardium, ${ }^{27-30}$ while Jph3 mutation caused Huntington's disease-like-2. ${ }^{31,32}$ Notably, strategies to maintain JPH2 level can prevent the progression from hypertrophy to heart failure, ${ }^{33}$ which highlights the potential therapeutic prospect of JPHs in beta cells in preventing the progress of type 2 diabetes. However, whether or not JPHs deficiency or mutation involves diabetic pathogenesis has so far not been proved.

The present study demonstrated that JPH3 is the major pancreatic isoform, which expressed in human and mouse pancreatic beta cells. In mouse islets, Jph3 deficiency caused the acute damage of GSIS, which was associated with the impairment of ER-mitochondria axis integrity. Therefore, our finding reveals a novel functional role for JPH3 in maintaining GSIS under physiological and probably pathological conditions.

\section{Results}

Mouse and human pancreatic beta cells express JPH3. To explore the expression of JPH subtypes in pancreas, in situ immunofluorescence double staining of four JPH isoforms or $\mathrm{JPH} 3$ and $\mathrm{JPH} 4$ alone with insulin was performed in mouse primary islets or human pancreatic tissues. JPH3 selectively coexpressed with insulin in mouse and human pancreatic beta cells (Figures $1 \mathrm{a}$ and b). Quantitative RTPCR (qRT-PCR) and Western blot assay further confirmed that only Jph3 or JPH3 existed in mouse islets (Figures 1c and d) (also see Supplementary Figure 1). By contrast, human pancreas expressed not only JPH3 but also slight JPH4 in some donors (two out of three) (Figure 1e). Since pancreatic tissue contains vascular smooth muscle expressing JPH2, we did not check JPH1 and JPH2 expression.

GSIS and mitochondrial condition in mouse si-Jph3 islets. To assess Jph3 silencing efficiency, protein level of JPH3 was determined by Western blot. JPH3 was knocked down in the islets by $69.33 \pm 0.17 \%$ at $48 \mathrm{~h}$ and $57.35 \pm 0.09 \%$ at $72 \mathrm{~h}$ compared with control (Figure $2 \mathrm{a}$ ). ELISA assay showed released insulin was $4.50 \pm 0.91$ or $2.83 \pm 0.53 \mathrm{ng} / \mathrm{ml} / \mathrm{h}$ per islet in si-Jph3 islets compared with $11.61 \pm 0.63$ or $5.68 \pm 0.36 \mathrm{ng} / \mathrm{ml} / \mathrm{h}$ per islet in $\mathrm{si}-C t r$ islets after incubated with $27.7 \mathrm{mmol} / \mathrm{L}$ (high) or $5.5 \mathrm{mmol} / \mathrm{L}$ (low) glucose, respectively (Figure $2 \mathrm{~b}$ ). This result indicated that acute attenuation of JPH3 dramatically impaired the GSIS. JPH3 was overexpressed in mouse islets by lentivirus (Supplementary Figure 2); however, GSIS was not affected in mouse Lenti-Jph3 islets (Supplementary Figure 3), suggesting that extra JPH3 expression might be unnecessary for GSIS under physiological condition.

Meanwhile, we investigated the mitochondrial function in si-Jph3 islets. Relative level of intracellular ATP induced by glucose was significantly affected in si-Jph3 islets (Figure 2c). Given that IP3R-mediated $\mathrm{Ca}^{2+}$ flux was closely associated with mitochondrial $\mathrm{Ca}^{2+}$ concentration $\left(\left[\mathrm{Ca}^{2+}\right]_{\mathrm{m}}\right)$ rise $^{34}$ and ATP generation, we further examined the IP3-evoked mitochondrial $\mathrm{Ca}^{2+}$ transient amplitude in permeabilized si-Jph3 islets. Representative fluorescence recordings showed that the initial slope and peak amplitude of $\left[\mathrm{Ca}^{2+}\right]_{\mathrm{m}}$ oscillations were considerably attenuated to $7.03 \pm 3.21$ and $52.02 \pm 21.67 \%$ in si-Jph3 islets compared with si-Ctr islets (Figure 2d). Considering that mitochondrial ATP synthesis is driven by $\Delta \Psi \mathrm{m},{ }^{5,6,10}$ we further observed $\Delta \Psi \mathrm{m}$ in si-Jph3 islets. Using fluorescence microscope, the global islet demonstrated mitochondria depolarization with low $\Delta \Psi$ (green) in si-Jph3 islet as compared with active mitochondria with high $\Delta \Psi$ (red) in si-Ctr islets (Figure 2e). Confocal laser fluorescence microscopy observation further exhibited several bigger bright-green sheets in si-Jph3 islet compared with si-Ctr islet (Figure 2e), zoom, which was consistent with the reduced GSIS in islets.

$\mathrm{Ca}^{2+}$-evoked GSIS and $\left[\mathrm{Ca}^{2+}\right]_{c}$ transient amplitude in si-Jph3 islets. To explore whether the impairment in GSIS observed in si-Jph3 islets is due to changes in intracellular $\mathrm{Ca}^{2+}$ levels, we measured $\mathrm{Ca}^{2+}$ signaling in response to glucose. All the chemicals-triggered insulin releases were significantly reduced in si-Jph3 islets (Figure 3a). Interestingly, CPA and IP3 evoked-insulin releases displayed increase $(2.29 \pm 0.50, \quad 3.30 \pm 0.52 \mathrm{ng} / \mathrm{ml} / \mathrm{h}$ per islet $)$ in si-Jph3 islets compared with $1.20 \pm 0.34 \mathrm{ng} / \mathrm{ml} / \mathrm{h}$ per islet in the control (si-Jph3) islets. By contrast, caffeine lost triggering effect on insulin releases in si-Jph3 islets (Figure 3a), suggesting a potential RyR2 $\mathrm{Ca}^{2+}$ signaling-dependent link between JPH3 expression and insulin secretion in islets. Chemicals-evoked $\left[\mathrm{Ca}^{2+}\right]_{c}$ transient amplitude were further evaluated in si-Jph3 islets. Quantification revealed that $\left[\mathrm{Ca}^{2+}\right]_{\mathrm{c}}$ transient amplitude was only blunted in response to caffeine in si-Jph3 islets (Figure $3 \mathrm{~b}$ ), characterized by the decrease in both initial slope and peak amplitude of $\left[\mathrm{Ca}^{2+}\right]_{\mathrm{c}}$ oscillations to $31.90 \pm 3.20$ and $32.80 \pm 3.29 \%$ compared with si-Ctr islets. The expression of $\mathrm{Ca}^{2+}$ channels or ATPase on ER was not affected in si-Jph3 islets (Figure 3c). The finding that JPH3 or RyR2 can be selectively coimmunoprecipitated with the use of anti-RyR2 or anti-JPH3 antibodies suggests direct binding and regulation of RyR2 by JPH3 in mouse and human pancreatic tissue (Figures $3 d$ and e). These data strongly suggested that Jph3 knockdown in islets selectively affected the RyR2- $\mathrm{Ca}^{2+}$ signaling. The $\left[\mathrm{Ca}^{2+}\right]_{\mathrm{c}}$ transient amplitude and insulin secretion was not affected in LentiJph3 islets in response to the chemicals (Supplementary Figure 4), indicating that extra JPH3 expression is unnecessary in $\mathrm{ER} \mathrm{Ca}^{2+}$ release under physiological condition.

Si-Jph3 disturbs ER-mitochondria contact and reduces Mfn2-related GSIS. The impairment of RyR2-Ca ${ }^{2+}$ signaling-related GSIS and mitochondrial function in 
a

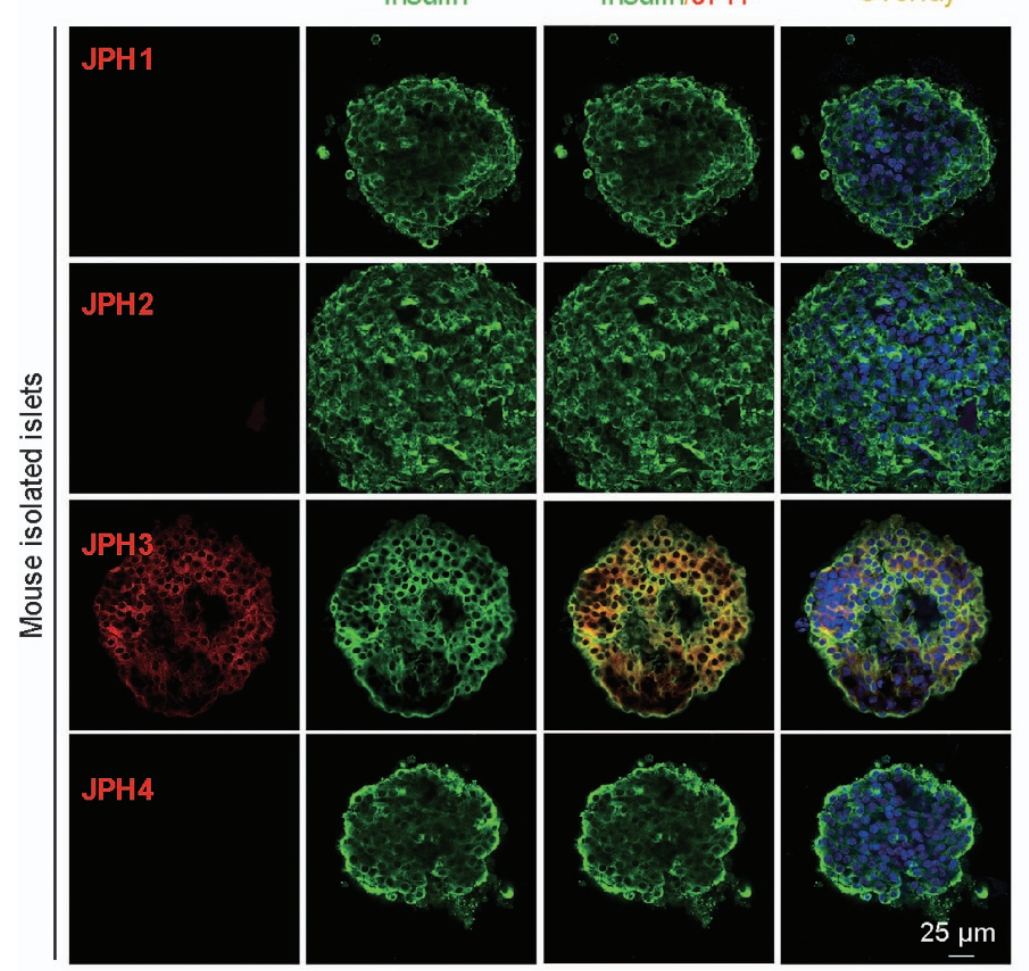

C

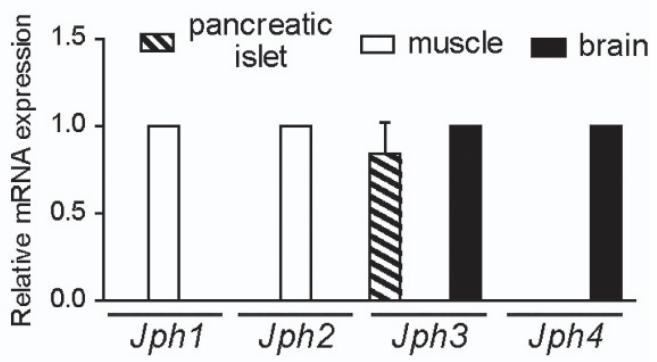

d

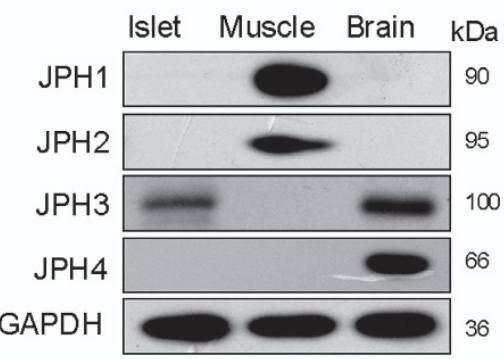

e

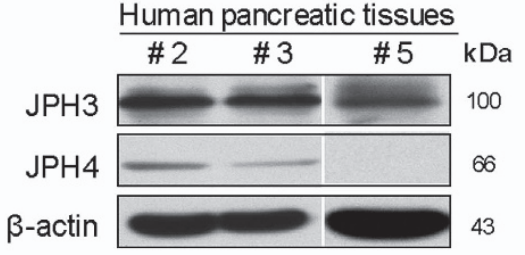

b

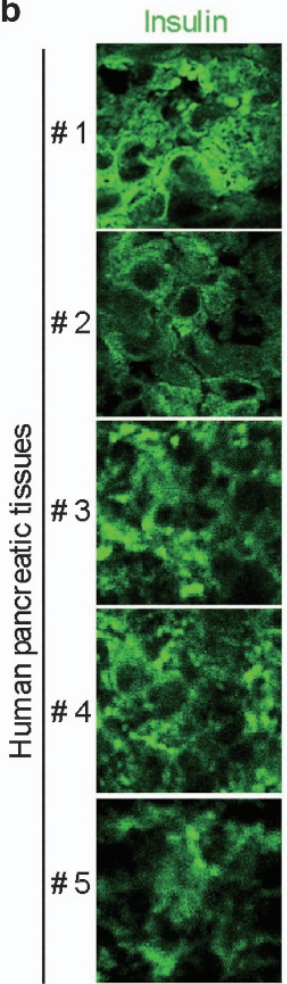

JPH3

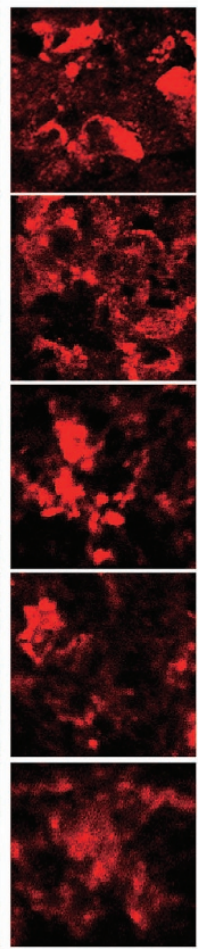

Insulin/JPH3

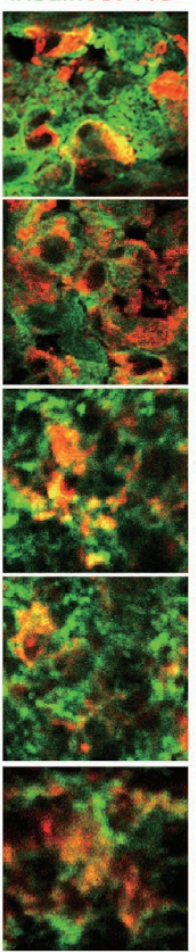

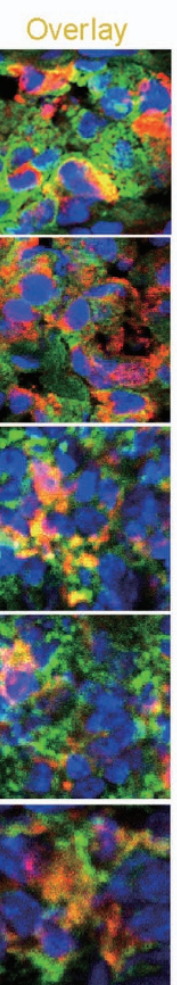

Insulin

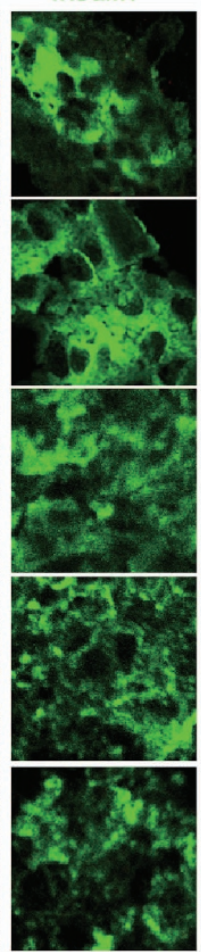

JPH4

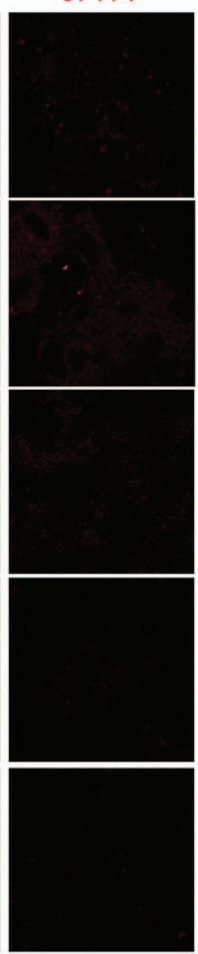

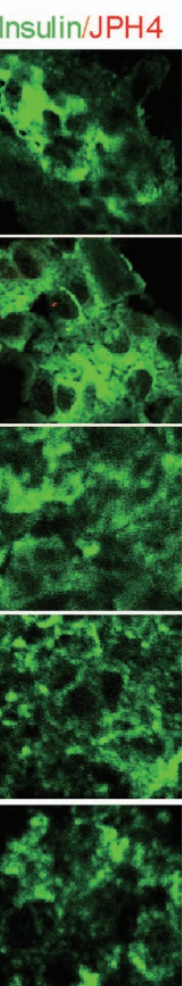

Overlay

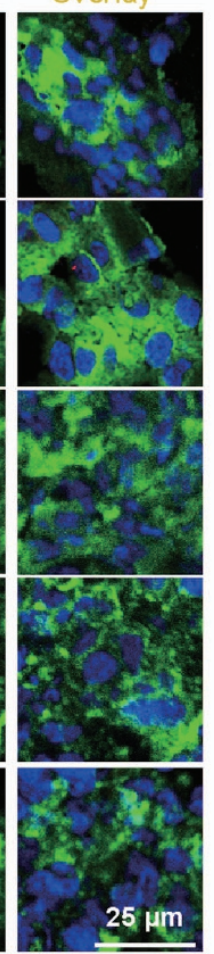

Figure $1 \mathrm{JPHs}$ expression identification. (a) JPH3 in mouse islets. (b) JPH3 in human pancreatic tissues. (c and d) Jph3 mRNA and JPH3 protein levels in mouse islets, mouse skeletal muscle and brain tissues as positive control. (e) JPH3 and JPH4 in human pancreatic tissues. Bar $=25 \mu \mathrm{m}$. See also Supplementary Table 1 for patient donor information 
a

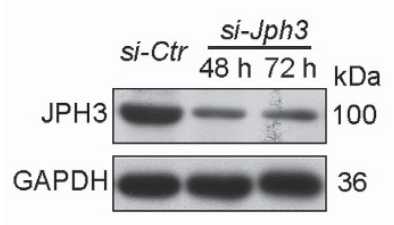

d

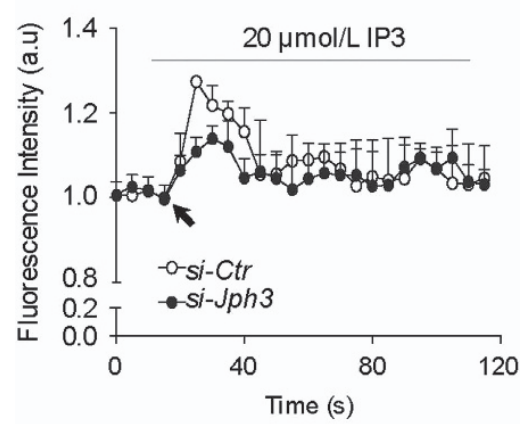

b
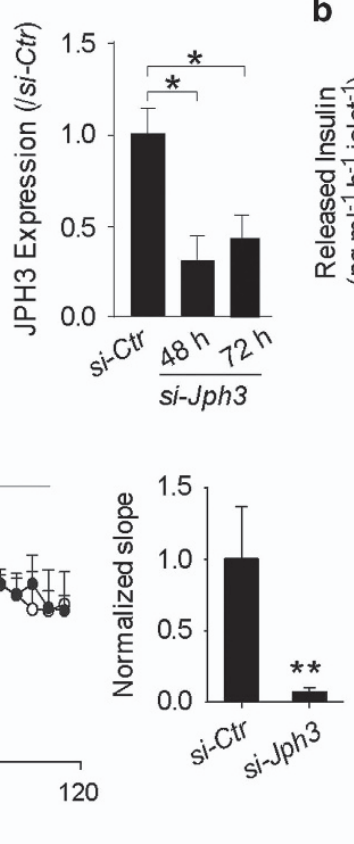

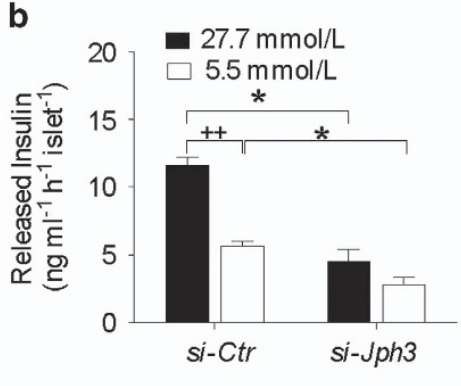

C

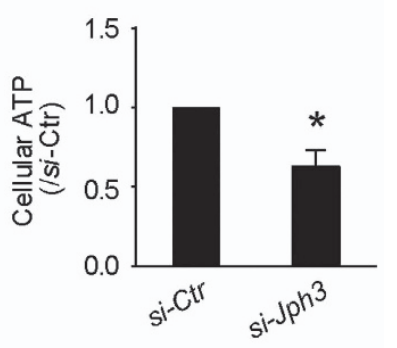

e
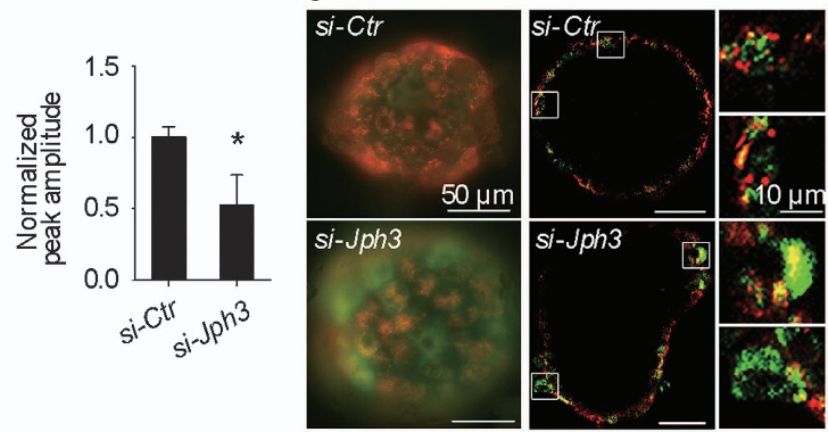

Figure 2 GSIS and mitochondrial function in si-Jph3 islets. (a) Jph3 silencing efficiency. (b) GSIS in response to high and low levels of glucose. (c) Intracellular ATP generation in the presence of glucose. (d) IP3-evoked $\left[\mathrm{Ca}^{2+}\right]_{\mathrm{m}}$ transients amplitude in permeabilized islets. Data are means \pm S.D. $n=3$ mice per group, with the minimum 30 islets for GSIS or 20 islets for ATP per mouse. ${ }^{*} P<0.05,{ }^{*} P<0.01$ versus si-Ctr. ${ }^{++} P<0.01$ versus $27.7 \mathrm{mmol} / \mathrm{L}$ glucose. (e) Global $\Delta \Psi \mathrm{m}$ in islets. Bar $=10 \mu \mathrm{m}$

a

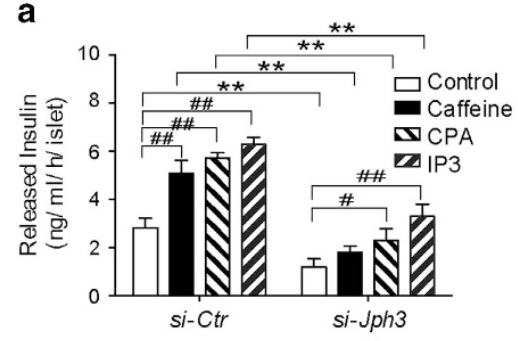

C
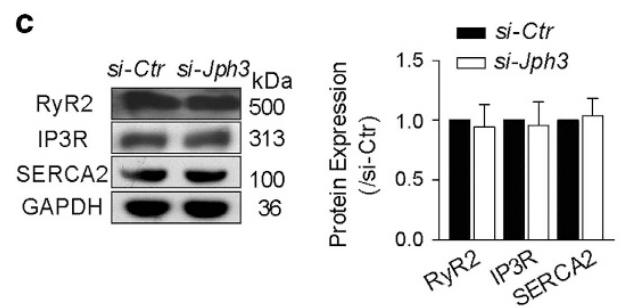
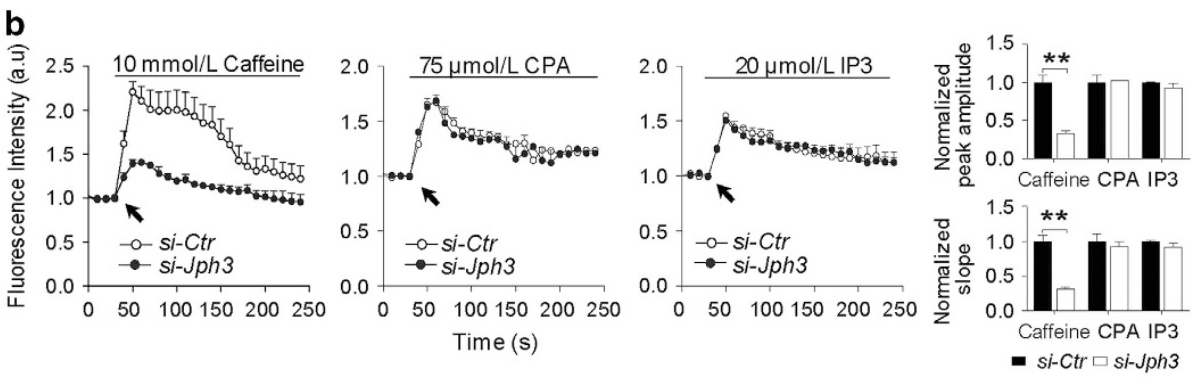

d
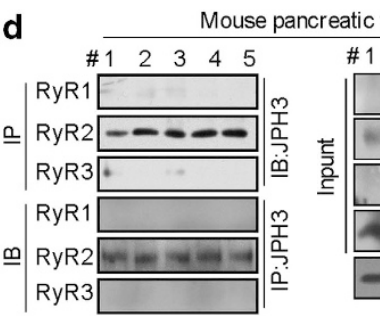

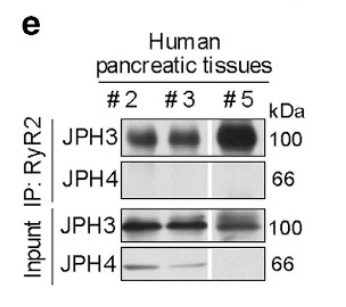

Figure 3 Insulin secretory response to $\mathrm{Ca}^{2+}$ signaling and $\left[\mathrm{Ca}^{2+}\right]_{\mathrm{c}}$ transient amplitude in si-Jph3 islets. (a) Insulin secretory response to $\mathrm{Ca}^{2+}$ signaling in the presence of glucose, and (b) $\left[\mathrm{Ca}^{2+}\right]_{\mathrm{c}}$ transient amplitude in response to chemicals. $n=3$ mice per group, with the minimum 30 islets per mouse for insulin secretion. (c) Expression of $\mathrm{Ca}^{2+}$ releasing proteins of ER $(n=3)$. (d and e) Co-immunoprecipitation showed JPH3 binds to RyR2 in mouse $(n=5)$ and human $(n=3)$ pancreatic tissues. Data are means \pm S.D. ${ }^{\star} P<0.05,{ }^{* *} P<0.01$ versus si-Ctr. ${ }^{\#} P<0.05,{ }^{\# \#} P<0.01$ versus control in the same group

si-Jph3 islets prompted us to address whether JPH3 could participate in ER-mitochondria tethering. Using transmission electron microscopy, we confirmed that PM-ER junctional contact and ER-mitochondria contact were present in mouse beta cells (rod-like crystal-containing cell). Both contacts were well organized in a PM-ER-mitochondria or ER-mitochondria status in beta cell of mouse pancreatic tissue (Supplementary Figure 5). Unfortunately, the total size of si-Jph3 islets harvested was too small to technically undergo the ultrastructural evaluation.

Considering the attenuated amplitude of $\left[\mathrm{Ca}^{2+}\right]_{\mathrm{m}}$ oscillation in si-Jph3 islet, we next observed the spatial organization of ER-mitochondria contact in si-Jph3 islets. The colocalization of ER (green) and mitochondria (red) fluorescent proteins 
a
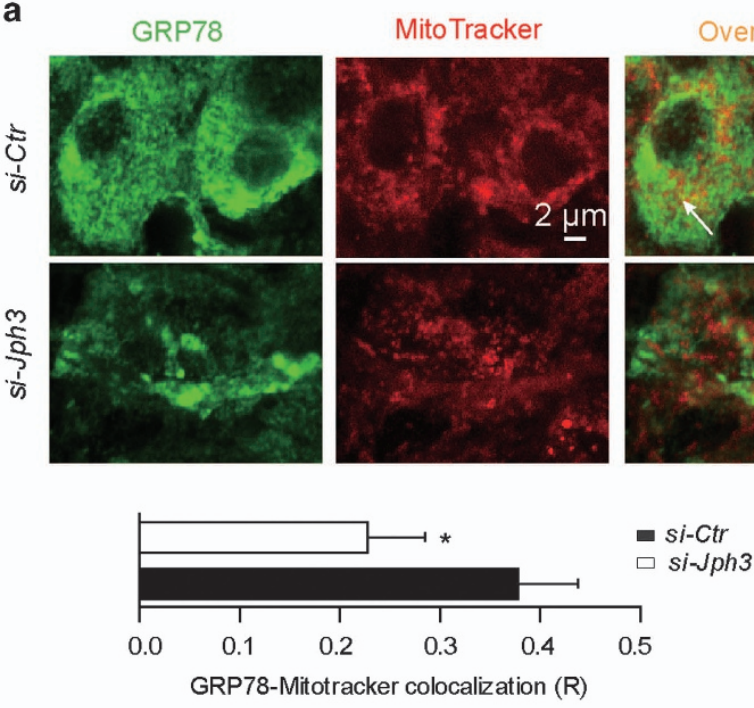

b

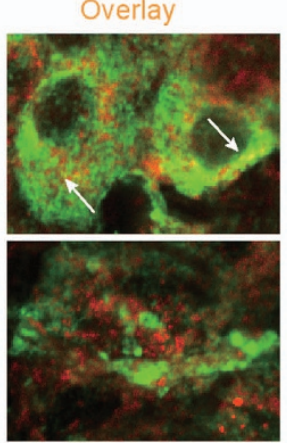

e

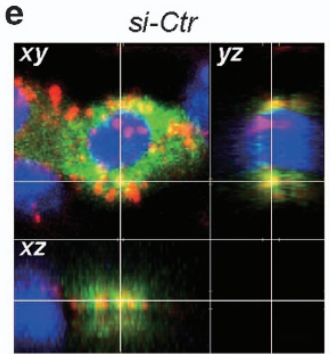

si-Ctr

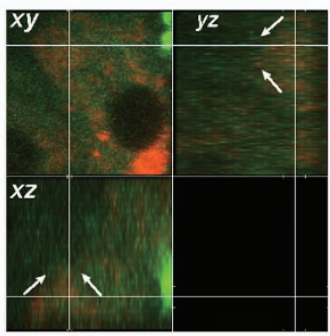

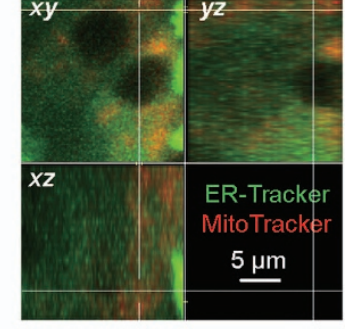

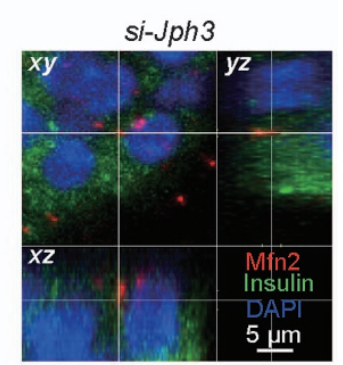

c

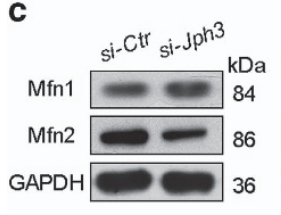

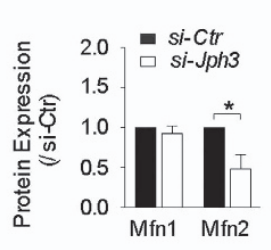

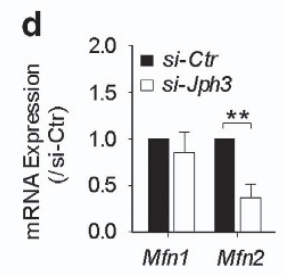

f

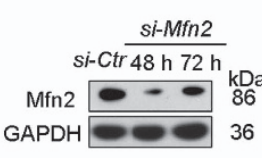

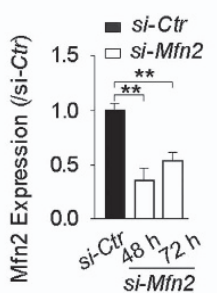

g

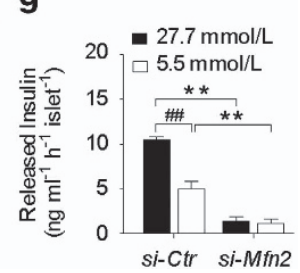

Figure 4 ER-mitochondria contact and Mfn2-dependent GSIS in si-Jph3 islets. (a) The colocalization of ER and mitochondria in islets. (b) 3D confocal images of ER-mitochondria contact. ( $\mathbf{c}$ and d) Mfn2 protein and Mfn2 mRNA expression $(n=3)$. (e) 3D confocal images of Mfn2 and insulin. (f) Mfn2 silencing efficiency ( $n=3$ ). (g) GSIS in si-Mfn2 islets, $n=3$ mice per group, with the minimum 30 islets per mouse. Data are means \pm S.D. ${ }^{*} P<0.05,{ }^{* *} P<0.01$ versus si-Ctr. ${ }^{\# \#} P<0.01$ versus 27.7 mmol/L glucose

display yellow area, which indicates that organelles are closer than $\sim 270 \mathrm{~nm}^{35}$ Confocal microscope observation demonstrated the colocalization areas of two organelles reduced by $43 \%$ in si-Jph3 islets compared with si-Ctr islets (Figure 4a). The laser scanning confocal microscope through $x y, x z$ and $y z$ axes further showed that ER-Tracker (green) and MitoTracker (red) contact in a perpendicular position in the cell of si-Ctr islet. By contrast, ER and mitochondria separated from each other and their contact disappeared in a cell of si-Jph3 islet (Figure 4b). All the data suggested that the spatial organized contact of ER and mitochondria was disrupted in si-Jph3 islets.

We further focused on the major proteins, Mfn1 and Mfn2, tethering the organelles for $\mathrm{Ca}^{2+}$ shuttling through InsP3gated channels from ER to mitochondria. Western blot analysis displayed that the expression level of Mfn2 was reduced to $47.84 \pm 18.47 \%$ in si-Jph3 islets compared with si-Ctr islets, but the expression of Mfn1 was unchanged (Figure 4c). Real-time RT-PCR analysis showed that Mfn2 expression level was also decreased to $54.37 \pm 5.53 \%$ in si-Jph3 islets (Figure 3d). Notably, Mfn2 was enriched in cytoplasm and colocalized with insulin in si-Ctrislets, but fewer Mfn2 presented in si-Jph3 islets (Figure 4e). To confirm whether the crucial effect of si-Jph3 on GSIS was partly due to reduced Mfn2 expression, we observed the influence of Mfn2 knockdown in GSIS of islets. Mfn2 was knocked down in the islets to $35.01 \pm 11.06 \%$ at $48 \mathrm{~h}$ (Figure $4 \mathrm{f}$ ), and insulin release in response to high or low level of glucose was $1.38 \pm 0.49$ or $1.12 \pm 0.54 \mathrm{ng} / \mathrm{ml} / \mathrm{h}$ per islet in si-Mfn2 islets compared with $10.53 \pm 0.27$ or $5.03 \pm 0.78 \mathrm{ng} / \mathrm{ml} / \mathrm{h}$ per islet in si-Ctr islets, respectively (Figure $4 \mathrm{~g}$ ). These results suggested that knockdown of Jph3 resulted in the impairment of ER-mitochondria contact, which did associate with Mfn2 downregulation and contribute to GSIS dysfunction. The overexpression of JPH3 did not alter Mfn1 and Mfn2 expression in islets (Supplementary Figure 6), suggesting that basic JPH3 expression is enough to maintain the juxtaposition of ER and mitochondria in islets.

Pgc-1a expression and localization in islets. We next explored the possible signaling involved in the impairment of Mfn2 expression in si-Jph3 islets. Sp1, Pgc-1a and Erra were believed to directly modulate Mfn2 expression in various tissues. ${ }^{36-38}$ Real-time RT-PCR assay showed that only Pgc-1a mRNA expression decreased to $49.25 \pm 5.98 \%$ in si-Jph3 islets compared with si-Ctr islets (Figure $5 a$ ), implying that Pgc-1a transcription might partly regulate Mfn2 expression in islets. But Western blot analysis demonstrated that Pgc-1a did not significantly change in expression in si-Jph3 islets (Figure 5b). Three-dimensional reconstruction by immunofluorescence image demonstrated that Pgc-1a distributed within nuclei in si-Ctr islets, but reduced in the nuclei 
a

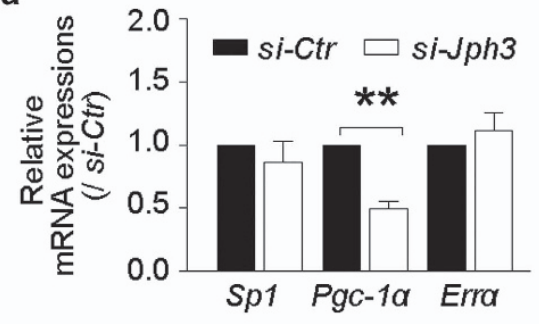

b

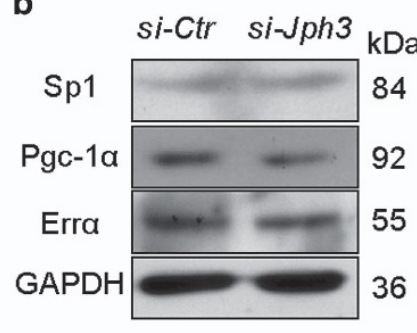

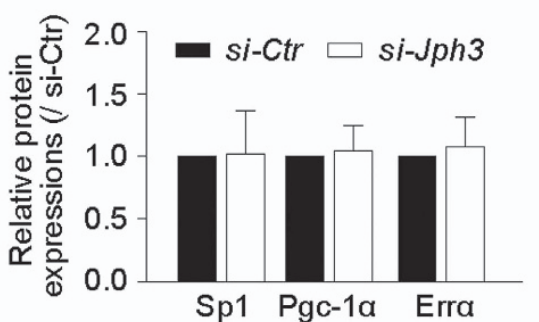

Sp1 Pgc-1a Erra

\section{c Pgc-1a/Insulin/DAPI Pgc-1a//nsulin}

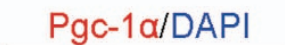

\section{D Reconstruction Transverse section}
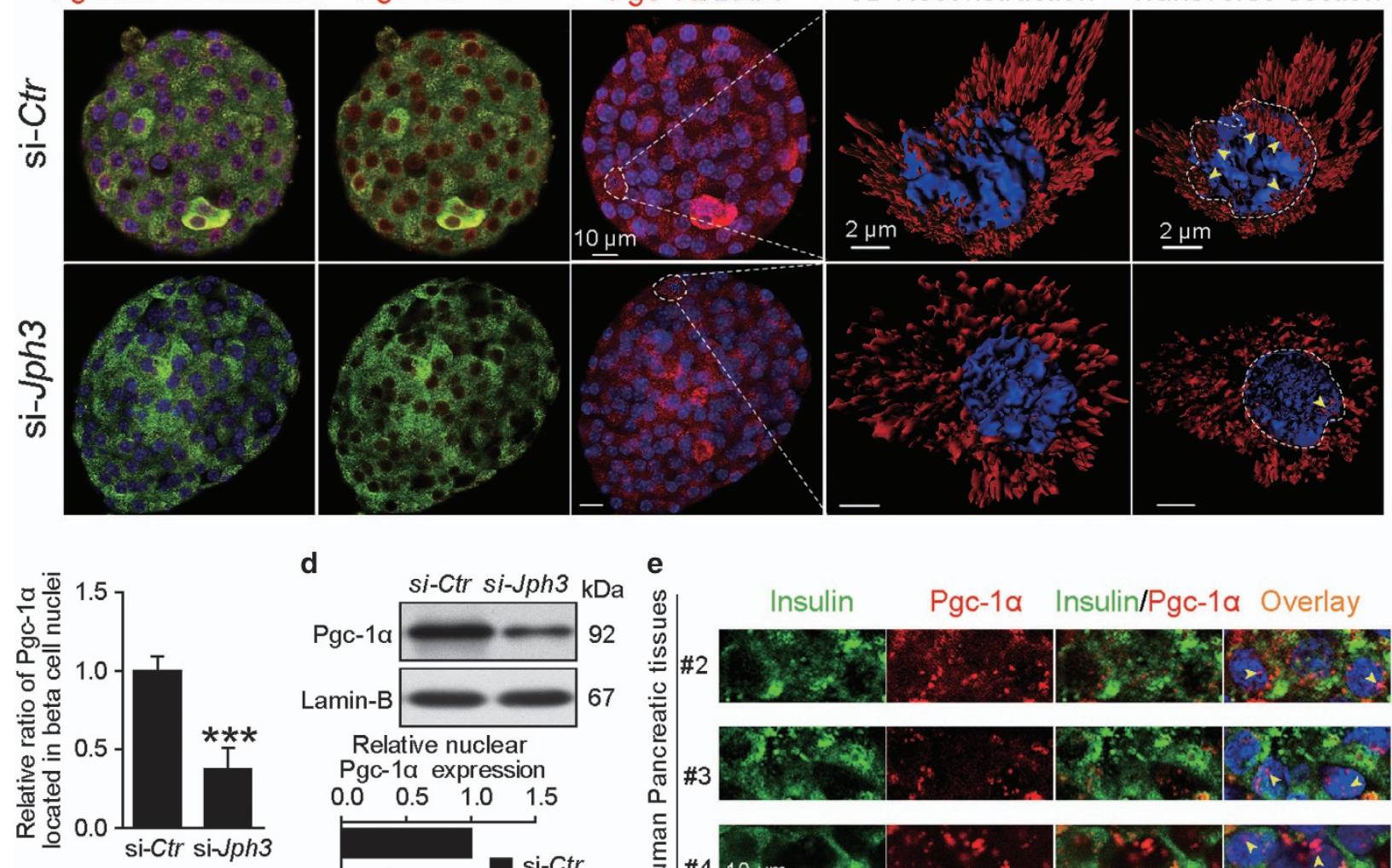

d

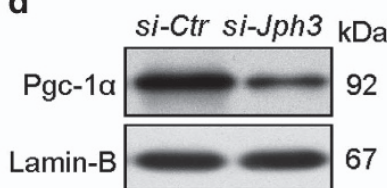

Relative nuclear

Pgc-1a expression
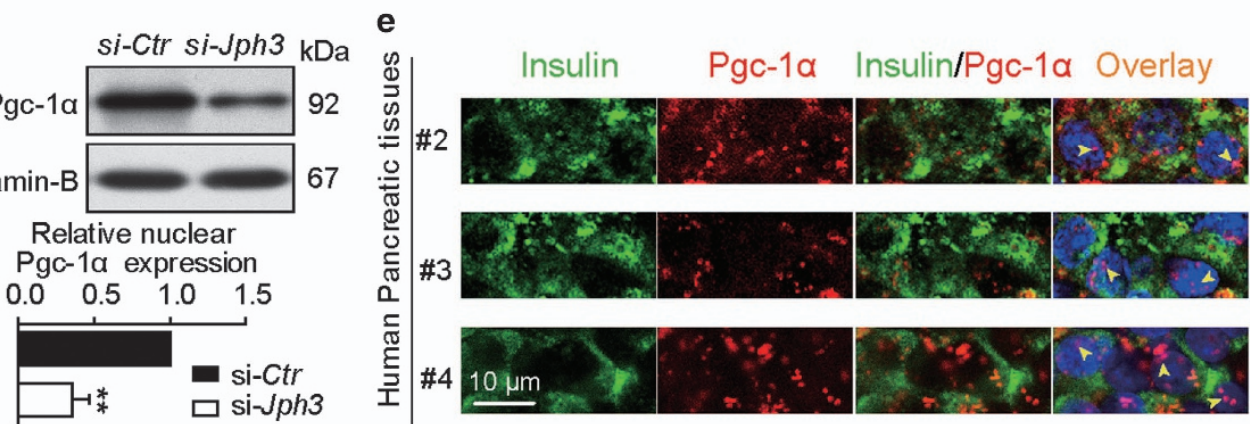

Figure 5 Pgc-1 $\alpha$ in islets. (a and b) Expressions of Pgc-1 $\alpha$ mRNA and Pgc-1 $\alpha$ protein $(n=3)$. (c) Confocal laser scanning exhibited the colocalization of Pgc-1 $\alpha$ with insulin in si-Ctr and si-Jph3 islets. Three-dimensional reconstruction and transverse section of a beta cell further displayed the localization of Pgc-1 $\alpha$ within a nucleus (yellow arrowhead). Ratio of Pgc-1 $\alpha$ existed in nuclei were showed in bar chart $(n=4)$. (d) Expression of nuclear Pgc- $1 \alpha$ in si-Ctr and si-Jph3 islets $(n=4)$. (e) Pgc- $1 \alpha$ existed in nuclei of human beta cells. Data are means \pm S.D. ${ }^{\star} P<0.05,{ }^{* *} P<0.01$ versus si-Ctr

of si-Jph3 islets (Figure 5c). Relative ratio of Pgc-1a localized in DAPI was decreased to $37.75 \pm 13.24 \%$ in si-Jph3 islets compared with si-Ctr islets (Figure $5 \mathrm{c}$ ). Moreover, the relative nuclear Pgc-1a expression level declined to $35.75 \pm 10.95 \%$ in si-Jph3 islets compared with si-Ctr islets as well (Figure 5d). The present results also indicated Pgc-1a nuclear translocation in the beta cells of mouse si-Ctr islet (Figure 5c) and existed in human pancreatic tissue with the possibility of nuclear translocation (without coexisting with insulin, Figure 5e). Pgc-1a coexpressed with PPAR $\beta$, a coactivator form, in nuclei of beta cells of human pancreatic tissue (Supplementary Figure 7), implying a possibility that RyR2-Ca ${ }^{2+}$ flux decrease could subsequently inhibit Pgc-1a activation in beta cells of si-Jph3 islets as mentioned in muscle. ${ }^{36}$
$\mathrm{Ca}^{2+}$ influx, ER stress or appoptosis-related protein expression in si-Jph3 islets. We next examined the effects of Jph3 knockdown on protein expression linking to $\mathrm{Ca}^{2+}$ influx, including STIM1 in ER, and Orai1 or LTCC in PM in mouse islets. Western blot assay demonstrated that none of them were altered in expression in si-Jph3 islets (Figure 6a) or Lenti-Jph3 islets (Supplementary Figure 8). Immunofluorescence image indicated that the overlay of STIM1 and Orai1 in si-Jph3 islets was similar to that in si-Ctr islets (Figure 6b), implying that the redistribution kinetics of the STIM1 binding to the Orai1 was unchanged in si-Jph3 islets.

Given that ER stress could result from Mfn2 ablation ${ }^{39}$ or intracellular $\mathrm{Ca}^{2+}$ homeostasis disorder, we next tested whether attenuated Mfn2 expression and RyR2-Ca ${ }^{2+}$ flux would indirectly lead to ER stress in si-Jph3 islets. Western 
a

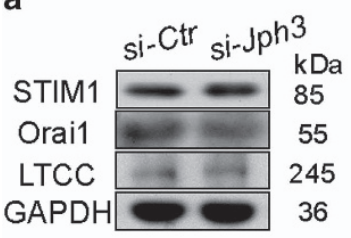

C

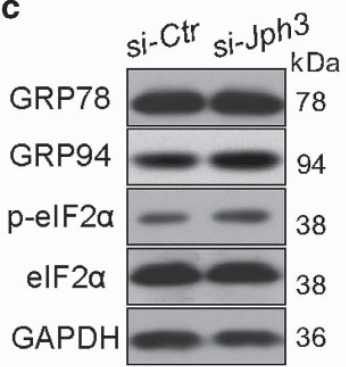

d

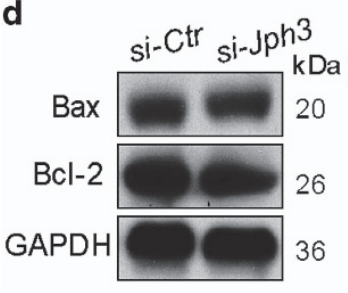

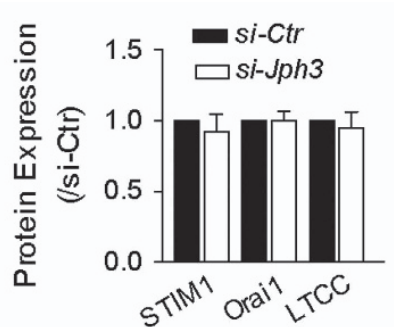
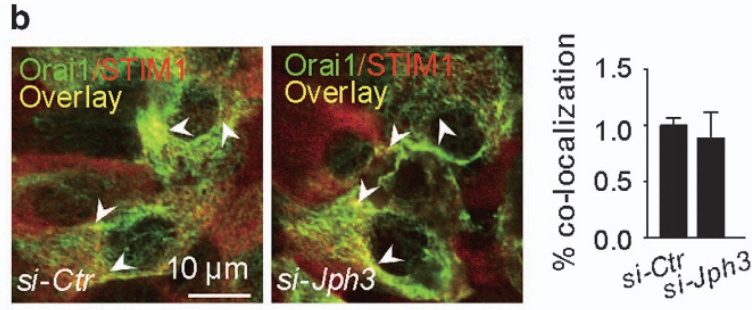
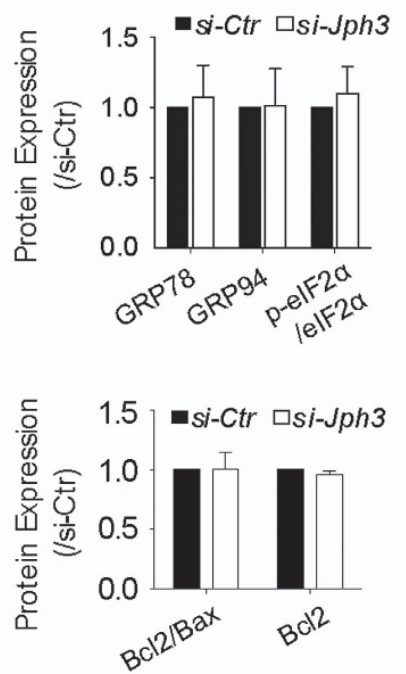

e

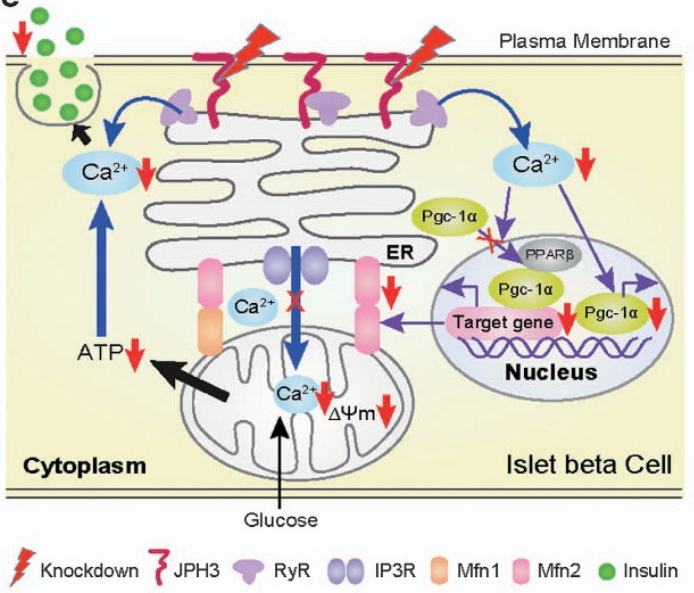

Figure $6 \mathrm{Ca}^{2+}$ influx and ER stress or Bcl-2/Bax-related proteins in si-Jph3 islets. Unchanged expression of $\mathrm{Ca}^{2+}$ influx-related proteins (a), colocalization areas (b), ER stress protein (c) Bcl-2/Bax ratio (d). $n=3$. (e) Schematic representation of the mechanism of JPH3-dependent GSIS in mouse beta cells

blot assay showed that the early ER stress proteins GRP78 and GRP94, or p-elF2 $a$ did not change in expression in si-Jph3 islets compared with si-Ctr islets (Figure 6c), suggesting that knockdown of Jph3 did not lead to ER stress in islets.

Anti-apoptotic $\mathrm{Bcl}-2$ and pro-apoptotic protein Bax were located in the ER-mitochondria interface, ${ }^{40}$ and low $\Delta \Psi \mathrm{m}$ could trigger apoptosis. Here, Western blot assay demonstrated that $\mathrm{Bcl}-2 / \mathrm{Bax}$ ratio was not changed in si-Jph3 islets (Figure 6d). The schematic representation of the mechanism of JPH3-dependent GSIS in beta cells was described in Figure $6 \mathrm{e}$.

\section{Discussion}

The present study demonstrates that $\mathrm{JPH} 3$ is the major isoform in pancreas, which expresses in mouse and human pancreatic beta cells. We conditionally reduce JPH3 protein level using RNA interference in islet, thereby partly disrupting JMC structure in beta cells. We demonstrate that JPH3 is important for supporting the normal secretory function of mouse pancreatic beta cells in vitro. Si-Jph3 in islets causes the impairment of mitochondrial function, decreases the insulin secretory response to $\mathrm{Ca}^{2+}$ signaling in the presence of glucose and reduces $\left[\mathrm{Ca}^{2+}\right]_{\mathrm{c}}$ transient amplitude in response to caffeine. Recently, a functional role for RyR2 in metabolism-secretion coupling both in mice and in humans is reported. Intracellular $\mathrm{Ca}^{2+}$ leak via RyR2 channels induces glucose intolerance associated with pancreatic beta cell
ER stress, mitochondrial dysfunction and decreased insulin secretion. ${ }^{1}$ Our finding reveals that the interaction between JPH3 and RyR2 in human and mouse pancreatic tissues, which implicates JPH3 as a new regulator of RyR2 function, and downregulation of JPH3 might directly lead to RyR2 $\mathrm{Ca}^{2+}$ leak and impair RyR2-Ca ${ }^{2+}$ signaling. We speculate that the si-Jph3 islets had defective $\mathrm{K}_{\text {ATP-independent insulin secre- }}$ tion, which was associated with a reduction in $\mathrm{RyR} 2-\left[\mathrm{Ca}^{2+}\right]_{\mathrm{C}}{ }^{-}$ related changes in GSIS and in glucose-stimulated increases in the ATP generation.

Impaired GSIS in islets is one of the characteristic features of type 2 diabetes mellitus. ${ }^{9}$ The effects of $\left[\mathrm{Ca}^{2+}\right]_{c}$ on GSIS are still subject to debate. Some previous studies suggested that intracellular store (including RyRs) plays a minor role in GSIS. ${ }^{18,41}$ Here, we show that acute knockdown of Jph3 directly leads to impaired GSIS accompanied by RyR2 $\mathrm{Ca}^{2+}$ insufficiency, indicating that JPH3 is critical for maintaining RyR2-Ca ${ }^{2+}$ signaling in GSIS.

Our study further demonstrates that impaired GSIS is associated with damaged mitochondrial function in si-Jph3 islets. Mitochondrial ATP synthesis is initiated by $\mathrm{Ca}^{2+}$ and driven by $\Delta \Psi \mathrm{m} .{ }^{10}$ In the presence of glucose, Jph3 knockdown in islets affects IP3 evoked-Ca ${ }^{2+}$ rapidly shuttling through IP3R into the mitochondrial matrix, where $\mathrm{Ca}^{2+}$ activates Krebs cycle enzymes, leading to decreased ATP production. Therefore, JPH3 expression should be essential for triggering GSIS through $\mathrm{K}_{\text {ATP-independent pathways. Our findings }}$ suggest that decrease of $\mathrm{JPH} 3$ is responsible for impaired 
GSIS, and also imply a causal link between JPH3 defects and type 2 diabetes.

The present results reveal that si-Jph3 in islets also attenuated Mfn2 expression, thereby disturbing the spatial organization of ER-mitochondria contact, which probably also contributes to insufficient GSIS. The ER-mitochondria axis has been defined in muscle from obese or type 2 diabetic patients. $^{42}$ Here, we further demonstrate that the spatial organized ultrastructural contacts of PM-ER-mitochondria do exist in mouse pancreatic beta cells, and that acute deficiency of JPH3 leads to alteration in ER-mitochondria contact morphology in islets. Moreover, IP3-evoked amplitude of $\left[\mathrm{Ca}^{2+}\right]_{\mathrm{m}}$ oscillations are considerably attenuated in permeabilized si-Jph3 islets, which suggests that the organization of VGCC and RyR2 within JMCs are probably functionally associated with ER-mitochondria contact via RyR2-Ca ${ }^{2+}$ signaling. Notably, our findings showed that although human pancreatic tissue expresses JPH3 and a few JPH4, only JPH3 can directly bind to RyR2 in human pancreatic tissues, which is consistent with the binding and functional response of RyR2 by JPH3 in mouse si-Ctr islets. Homotypic and heterotypic interactions between Mfn2 on the ER and Mfn1 and 2 on mitochondria enable $\mathrm{Ca}^{2+}$ microdomains around open IP3R to propagate rapidly into the mitochondrial matrix, thereby increasing ATP production. ${ }^{10,43}$ Our findings further reveal that although both Mfn1 and Mfn2 abundantly express in beta cells, Jph3 knockdown in islets only selectively affects Mfn2 expression and Mfn2 transcription. Furthermore, acute knockdown of Mfn2 directly leads to impaired GSIS in islet, which highlights the possibility that decrease in Mfn2 expression due to JPH3 downregulation in beta cells might cause development of type 2 diabetes. Collectively, our findings, for the first time, suggest that the structural and functional ER-mitochondria axis integrity is of importance to maintain GSIS, and that Jph3 knockdown significantly affects Mfn2 expression and subsequently influences the mitochondria function in beta cells.

Our study demonstrates that, among the three examined Mfn2 modulators, Jph3 knockdown in islets selectively affects Pgc-1a mRNA expression at the transcription level. Previous researches demonstrated that the raise of intracellular $\mathrm{Ca}^{2+}$ concentration contributes to Pgc-1a nuclear translocation and transcription in myocytes and skeletal muscle. ${ }^{36,44}$ PGC-1a takes part in shaping mitochondrial participation in calcium signalling that underlies its protective role against stress and proapoptotic stimuli in pathophysiological conditions. ${ }^{45}$ In addition, reduced RyR2 signaling can alter cardiac transcriptional programming, including $P g c$-1a down-regulation, in a manner associated with cardiac pathology, ${ }^{23}$ and also cause abnormal $\mathrm{Ca}^{2+}$ handling in type 2 diabetic conditions. ${ }^{17}$ Our study further suggests that knockdown of Jph3 might contribute to RyR2 $\mathrm{Ca}^{2+}$ signaling-related Mfn2 reduction via weakened Pgc-1a signaling in pancreatic beta cells. Taken together, JPH3 takes an important role in maintaining the suitable distance and crosstalk between ER and mitochondria via Pgc-1 a pathway in beta cells. Recently, it is revealed that a Pgc-1 $a$-PPAR $a / \delta$ partnership in nuclei can promote the target molecules transcription in skeletal muscle. ${ }^{46}$ PPAR $\beta$ activation can also promote human and mouse embryonic stem cells differentiating into functional insulin-positive cells. ${ }^{47}$ Our findings imply that Pgc-1 $a$ and PPAR $\beta$ in the nuclei of beta cells in human pancreatic tissue might act as co-activators, thereby contributing to regulating Mfn2 expression. Therefore, it is valuable to further explore whether JPH3 takes a role in human GSIS in the future.

The present study showed that the protein expression and redistribution kinetics of the STIM1 binding to the Orai1 are unchanged in si-Jph3 islets, indicating that Jph3 knockdown does not affect store-operated $\mathrm{Ca}^{2+}$ entry function. In addition, si-Jph3 caused Mfn2 attenuation or RyR2-Ca ${ }^{2+}$ insufficiency does not lead to ER stress and apoptosis-related protein expression, suggesting that GSIS insufficiency should not result from ER stress or apoptosis in si-Jph3 islets.

In conclusion, JPH3 is the major pancreatic isoform expressed in both human and mouse pancreatic beta cells. Our findings suggested the physiological roles of JPH3 in beta cells and implicated JPH3 as an important candidate involved in the impairment of GSIS in type 2 diabetic conditions. Strategies to maintain JPH2 level can prevent the progression from hypertrophy to heart failure. ${ }^{33}$ Therefore, the dual functional roles for JPH3 in pancreatic beta cells, linking PM-ER and interaction with RyR2, may have implications for the development of new therapeutic strategies for type 2 diabetes.

\section{Materials and Methods}

Mouse pancreatic islet isolation. Eight-week-old male Balb/c mice were obtained from the Experimental Animal Center, Zhejiang University, China (Grade II, Certificate № SCXK 2008-0016). The experiments were conducted under the Guide for the care and use of laboratory animals (2011), and a protocol approved by the Institutional Animal Care and Use Committee of Zhejiang University (№ ZJU-2015-435-01), China. Islets were isolated by ductal collagenase V (Sigma Aldrich, St. Louis, MO, USA) injection from fully anesthetized mice ${ }^{48}$ and cultured in RPMI 1640 containing 20\% FBS for further investigation.

Human pancreatic tissue. Human pancreatic samples surrounding the cut tissues were obtained from surgical donors under prior informed consent procedure and with written consent from the Human Ethics Committee of the 2nd Affiliated Hospital (№ 2015-029), College of Medicine, Zhejiang University, China. Frozen $10 \mu \mathrm{m}$ consecutive sections were cut for immunocytochemistry analysis. Patient information could be found in Supplementary Table 1.

Transfections with siRNA. Isolated islets were transfected with $100 \mathrm{nM}$ siRNA against Jph3, Mfn2 or negative control siRNA (si-Ctr) (Life Technologies, Carlsbad, CA, USA) using Lipofectamine RNAiMAX (Life Technologies) transfection agent according to the manufacturer's instructions. Sequences for siRNA were shown in Supplementary Table 2.

Immunofluorescence image analysis. All immunostaining was conducted as previously described. ${ }^{47}$ Samples were probed with the primary antibodies as follows: Insulin, GRP78, STIM1 (Cell Signaling Technology, Danvers, MA, USA); JPH1, JPH2 (Thermo Fisher Scientific, Waltham, MA, USA); JPH3, JPH4, Mfn1, Mfn2, PPAR, Pgc-1 $\alpha$ (Abcam, Cambridge, MA, USA); Orai1 (Pierce, Rockford, IL, USA). Then islets were incubated with secondary antibodies and DAPI (Sigma Aldrich). Images were acquired under Leica DMI3000B microscope (Leica Microsystems, Wetzlar, Germany) or Olympus FV1000 confocal microscope (CLSM, Olympus, Hertforshire, UK). Colocalization ratio of GRP78 and MitoTracker was calculated by Metamorph software (Molecular Devices, Sunnyvale, CA, USA) automatically. Relative ratio of Pgc-1 $\alpha$ nuclear translocation was analyzed by Imaris software (Bitplane, Zurich, Switzerland).

Western blot and coimmunoprecipitates analysis. Western blot was performed as previously described. ${ }^{47}$ Typically, sample lysates were resolved in SDS-PAGE and transferred onto PVDF membrane (Merck Millipore, Billerica, MA, USA). The PVDF membranes were incubated with the following primary antibodies 
(in addition to the above-mentioned): Err $\alpha$, Sp1, IP3R, LTCC, Lamin B (Santa Cruz Biotechnology, CA, USA); RyR1, RyR2, RyR3 (Merck Millipore); SERCA2, GRP94, elF2 $\alpha$, p-elF2 $\alpha$, Bcl-2, Bax (Cell Signaling Technology); JPH1, JPH2, JPH3, JPH4, Mfn1, Mfn2, Pgc-1 $\alpha$ (Abcam, Cambridge, MA, USA); GAPDH (Multisciences, Shanghai, China). Then samples were incubated with HRP-conjugated secondary antibodies (LK-GAM007, LK-GAR007, LK-RAG007, MULTISCIENCES). Blots were developed using enhanced chemiluminescence reagents (Pierce). Coimmunoprecipitates were analyzed by immunoblotting, using either anti-JPH3 or anti-RyR1, 2, 3 antibodies to detect the interaction between JPH3 and 3 RyR subtypes.

RT-PCR analysis. Total RNA was isolated by Trizol (Life Technologies). For sqRT-PCR, reverse transcription was performed using M-MuLV first strand cDNA synthesis kit, and real-time PCR was performed using the PCR kit (Sangon, Shanghai, China). For qRT-PCR, RNA was treated by RT reagent kit (RR047A), and amplifications were performed using SYBR Premix Ex Taq Kit (TAKARA, Dalian, China). Primer sequences were displayed in Supplementary Tables 3 and 4.

ELISA assay of GSIS. Islets were precultured in Krebs' Ringer Bicarbonate HEPES buffer containing $2.5 \mathrm{mmol} / \mathrm{L}$ glucose for $1 \mathrm{~h}$. Cells were treated with different reagents for another hour. The supernatant was analyzed by Rat/Mouse Insulin ELISA Kit (\#EZRMI-13 K, Millipore). The reagents were as follows: glucose $27.7 \mathrm{mmol} / \mathrm{L}$ or $5.5 \mathrm{mmol} / \mathrm{L}$ dissolved in $\mathrm{KRBH}$ buffer; $5 \mathrm{mmol} / \mathrm{L}$ caffeine (Zhejiang Institute for Food and Drug Control, Hangzhou, Zhejiang), $50 \mu \mathrm{mol} / \mathrm{L}$ Cyclopiazonic acid (CPA, Tocris, Bristol, UK) and $10 \mu \mathrm{mol} / \mathrm{L}$ D-myo-inositol-1,4,5-trisphosphate (IP3) (Tocris) dissolved in KRBH buffer containing 2.5 mmol/L glucose. The Krebs' Ringer Bicarbonate HEPES buffer consisted of $160 \mathrm{ml}$ Buffer A, $200 \mathrm{ml}$ Buffer B, $2.4 \mathrm{~g} \mathrm{HEPES}$, and $2 \mathrm{~g} \mathrm{BSA}$ in a total volume of $1000 \mathrm{ml}$ deionized water and filtered via $0.45 \mu \mathrm{m}$ and $0.22 \mu \mathrm{m}$ membranes. The Buffer A consisted of $34.6 \mathrm{~g} \mathrm{NaCl}, 1.8 \mathrm{~g}$ $\mathrm{KCl}, 1.9 \mathrm{~g} \mathrm{CaCl}_{2}, 0.8 \mathrm{~g} \mathrm{KH}_{2} \mathrm{PO}_{4}, 1.5 \mathrm{~g} \mathrm{MgSO}_{4} \bullet 7 \mathrm{H}_{2} \mathrm{O}$ in $1000 \mathrm{ml}$ deionized water. The Buffer $\mathrm{B}$ consisted of $13 \mathrm{~g} \mathrm{NaHCO}_{3}$ in $1000 \mathrm{ml}$ deionized water. Typically, for IP3 effect evaluation, islets were pretreated with $20 \mu \mathrm{g} / \mathrm{ml}$ digitonin (Sigma Aldrich) for $30 \mathrm{~min}$.

$\mathrm{Ca}^{2+}$ transient measurement. Islets were loaded with X-rhod-1 AM $(5 \mu \mathrm{mol} / \mathrm{L})$ and Rhod-2 $(5 \mu \mathrm{mol} / \mathrm{L})$ (Life Technologies) for $\left[\mathrm{Ca}^{2+}\right]_{\mathrm{c}}$ and $\left[\mathrm{Ca}^{2+}\right]_{\mathrm{m}}$ (mitochondrial matrix $\mathrm{Ca}^{2+}$ ) indicator, respectively. Digitonin-permeabilized islets were used for IP3 experiment. Caffeine, CPA and IP3 were added to elicit $\mathrm{Ca}^{2+}$ release. Images were analyzed using software InVivo under live cell imaging system (IX S1, Olympus) by measuring fluorescence of individual islet at $549 \mathrm{~nm}$ and $576 \mathrm{~nm}$, respectively. All analyses were processed as the relative fluorescence intensity. The slopes (from initiation to top) derived from the linear equation were calculated by Excel.

Cellular ATP assay. Islets were incubated with $2.5 \mathrm{mmo} / \mathrm{L}$ glucose for 60 min. ${ }^{49}$ Then cells were analyzed by ATP bioluminescence assay kit (A095, Nanjing Jiancheng, China) following the manufacturer's instructions.

Mitochondrial membrane potential $\left(\Delta \boldsymbol{\Psi}_{\mathrm{m}}\right)$ measurement. For the determination of $\Delta \Psi \mathrm{m}$, cells were incubated with $2 \mu \mathrm{g} / \mathrm{ml} \mathrm{JC}-1\left(5,5^{\prime}, 6,6^{\prime}\right.$ - tetrachloro1,1',3,3'-tetraethyl-benzimidazolylcarbocyanine iodide, T-4069, Sigma Aldrich) for $30 \mathrm{~min}$ at $37^{\circ} \mathrm{C}$ in the dark. Cells were then washed by PBS and observed under Leica DMI3000B microscope. The red fluorescent J-aggregate indicates normal $\Delta \Psi \mathrm{m}$, while the green monomer fluorescence demonstrates low $\Delta \Psi \mathrm{m}$.

Mitochondrion or ER probes staining. Islets were incubated with MitoTracker and ER-Tracker (Life Technologies) for $30 \mathrm{~min}$ following the manufacturer's instructions. Sections were photographed under Leica DMI3000B microscope (Leica Microsystems, Wetzlar, Germany) or Olympus FV1000 confocal microscope (CLSM, Olympus, Hertforshire, UK).

Statistical analysis. Data were reported as means \pm S.D. Experiments were performed three times as repeats, and each time the islets were obtained from different mice. Comparisons of two groups used two-tailed student's $t$-test. Comparisons of multiple groups used ANOVA (GraphPad Prism 6; GraphPad software, San Diego, CA, USA). The differences were considered significant at $P<0.05$.

\section{Conflict of Interest}

The authors declare no conflict of interest.
Acknowledgements. The authors would wish to thank Professor Zhong Chen (Department of Pharmacology, Key Laboratory of Medical Neurobiology of the Ministry of Health of China, College of Pharmaceutical Sciences, Zhejiang University, Hangzhou, China) and Erging Wei (Department of Pharmacology and Institute of Neuroscience, College of Medicine, Zhejiang University, Hangzhou, China) for technical support in frozen section procedure and $\mathrm{Ca}^{2+}$ transient measurement, respectively. The authors are also grateful to The Core Facilities of Zhejiang University School of Medicine for technical assistance with confocal laser fluorescence microscopy. This work was supported by National Natural Science Foundation of China (№ 81573513, № 81173135, № 30973600 to Y. Lou), and by Zhejiang Provincial Natural Science Foundation of China (№ LZ12H31001 to Y. Lou).

\section{Author contributions}

$\mathrm{LL}$ and ZFP performed all the experiments in the Lab, and validated human pancreatic tissues, researched the data, contributed to the statistical analysis and discussion; XH wrote the primary manuscript and contributed to the discussion; BWW and TL optimized some key technological steps; MXK aided with the performing surgical operation under prior informed consent procedure of patients; RSG contributed to the discussion and reviewed the manuscript; XYH, YHZ, LJG and DYZ aided with the experimental arrangements and technological works; YLW performed the surgical operation and confirmed the non-cancer samples surrounding the cut tissues under prior informed consent procedure of patients with pancreatic cancer; YJL conceived of and designed the constructs, researched the data, cooperated with clinical research, reviewed and edited the manuscript.

1. Santulli G, Pagano G, Sardu C, Xie W, Reiken S, D'Ascia SL et al. Calcium release channel RyR2 regulates insulin release and glucose homeostasis. J Clin Invest 2015; 125: 4316.

2. Allagnat $F, K$ Klee $P$, Cardozo AK, Meda $P$, Haefliger JA. Connexin36 contributes to INS-1E cells survival through modulation of cytokine-induced oxidative stress, ER stress and AMPK activity. Cell Death Differ 2013; 20: 1742-1752.

3. Ravier MA, Daro D, Roma LP, Jonas JC, Cheng-Xue R, Schuit FC et al. Mechanisms of control of the free $\mathrm{Ca} 2+$ concentration in the endoplasmic reticulum of mouse pancreatic beta-cells: interplay with cell metabolism and [Ca2+]c and role of SERCA2b and SERCA3. Diabetes 2011; 60: 2533-2545.

4. Luciani DS, Gwiazda KS, Yang TL, Kalynyak TB, Bychkivska Y, Frey MH et al. Roles of IP3R and RyR Ca2+ channels in endoplasmic reticulum stress and beta-cell death. Diabetes 2009; 58: 422-432

5. Demozay D, Tsunekawa S, Briaud I, Shah R, Rhodes CJ. Specific glucose-induced control of insulin receptor substrate-2 expression is mediated via Ca2+-dependent calcineurin/NFAT signaling in primary pancreatic islet beta-cells. Diabetes 2011; 60: 2892-2902.

6. Henquin JC. Triggering and amplifying pathways of regulation of insulin secretion by glucose. Diabetes 2000; 49: 1751-1760.

7. Bokvist K, Eliasson L, Ammala C, Renstrom E, Rorsman P. Co-localization of L-type $\mathrm{Ca} 2+$ channels and insulin-containing secretory granules and its significance for the initiation of exocytosis in mouse pancreatic B-cells. Embo J 1995; 14: 50-57.

8. Davalli AM, Biancardi E, Pollo A, Socci C, Pontiroli AE, Pozza G et al. Dihydropyridinesensitive and -insensitive voltage-operated calcium channels participate in the control of glucose-induced insulin release from human pancreatic beta cells. J Endocrinol 1996; 150: 195-203.

9. Seino S, Shibasaki T, Minami K. Dynamics of insulin secretion and the clinical implications for obesity and diabetes. J Clin Invest 2011; 121: 2118-2125.

10. Quan X, Nguyen TT, Choi SK, Xu S, Das R, Cha SK et al. Essential role of mitochondrial $\mathrm{Ca} 2+$ uniporter in the generation of mitochondrial $\mathrm{pH}$ gradient and metabolism-secretion coupling in insulin-releasing cells. J Biol Chem 2015; 290: 4086-4096.

11. Prentki M, Matschinsky FM, Madiraju SR. Metabolic signaling in fuel-induced insulin secretion. Cell Metab 2013; 18: 162-185.

12. Maechler P. Mitochondrial function and insulin secretion. Mol Cell Endocrinol 2013; 379: $12-18$.

13. Takeshima H, Hoshijima M, Song LS. Ca(2+) microdomains organized by junctophilins. Cell Calcium 2015; 58: 349-356.

14. Franzini-Armstrong $\mathrm{C}$, Protasi $\mathrm{F}$, Ramesh V. Shape, size, and distribution of $\mathrm{Ca}(2+)$ release units and couplons in skeletal and cardiac muscles. Biophys $J$ 1999; 77: 1528-1539.

15. Takeshima $H$, Komazaki S, Nishi M, lino M, Kangawa K. Junctophilins: a novel family of junctional membrane complex proteins. Mol Cell 2000; 6: 11-22.

16. Nishi M, Hashimoto K, Kuriyama K, Komazaki S, Kano M, Shibata $S$ et al. Motor discoordination in mutant mice lacking junctophilin type 3. Biochem Biophys Res Commun 2002: 292: 318-324.

17. Dixit SS, Wang T, Manzano EJ, Yoo S, Lee J, Chiang DY et al. Effects of CaMKII-mediated phosphorylation of ryanodine receptor type 2 on islet calcium handling, insulin secretion, and glucose tolerance. PLOS ONE 2013; 8: e58655.

18. Johnson JD, Kuang S, Misler S, Polonsky KS. Ryanodine receptors in human pancreatic beta cells: localization and effects on insulin secretion. Faseb J 2004; 18: 878-880. 
19. Komazaki S, Ito K, Takeshima H, Nakamura H. Deficiency of triad formation in developing skeletal muscle cells lacking junctophilin type 1. Febs Lett 2002; 524: 225-229.

20. Ito K, Komazaki S, Sasamoto K, Yoshida M, Nishi M, Kitamura K et al. Deficiency of triad junction and contraction in mutant skeletal muscle lacking junctophilin type 1. J Cell Biol 2001; 154: 1059-1067.

21. van Oort RJ, Garbino A, Wang W, Dixit SS, Landstrom AP, Gaur N et al. Disrupted junctional membrane complexes and hyperactive ryanodine receptors after acute junctophilin knockdown in mice. Circulation 2011; 123: 979-988.

22. Moriguchi S, Nishi M, Komazaki $\mathrm{S}$, Sakagami $\mathrm{H}$, Miyazaki $\mathrm{T}$, Masumiya $\mathrm{H}$ et al Functional uncoupling between $\mathrm{Ca} 2+$ release and afterhyperpolarization in mutant hippocampal neurons lacking junctophilins. Proc Natl Acad Sci U S A 2006; 103: 10811-10816.

23. Bround MJ, Wambolt R, Luciani DS, Kulpa JE, Rodrigues B, Brownsey RW et al. Cardiomyocyte ATP production, metabolic flexibility, and survival require calcium flux through cardiac ryanodine receptors in vivo. J Biol Chem 2013; 288: 18975-18986.

24. Maret S, Dorsaz S, Gurcel L, Pradervand S, Petit B, Pfister $C$ et al. Homer1a is a core brain molecular correlate of sleep loss. Proc Natl Acad Sci U S A 2007; 104: 20090-20095.

25. Jung SR, Reed BJ, Sweet IR. A highly energetic process couples calcium influx through L-type calcium channels to insulin secretion in pancreatic beta-cells. Am J Physiol Endocrinol Metab 2009; 297: E717-E727.

26. Islam MS. Calcium signaling in the islets. Adv Exp Med Biol 2010; 654: 235-259.

27. Landstrom AP, Kellen CA, Dixit SS, van Oort RJ, Garbino A, Weisleder N et al. Junctophilin-2 expression silencing causes cardiocyte hypertrophy and abnormal intracellular calciumhandling. Circ Heart Fail 2011; 4: 214-223.

28. Matsushita $Y$, Furukawa T, Kasanuki $H$, Nishibatake M, Kurihara $Y$, Ikeda A et al. Mutation of junctophilin type 2 associated with hypertrophic cardiomyopathy. J Hum Genet 2007; 52: 543-548.

29. Landstrom AP, Weisleder N, Batalden KB, Bos JM, Tester DJ, Ommen SR et al. Mutations in $\mathrm{JPH} 2$-encoded junctophilin-2 associated with hypertrophic cardiomyopathy in humans. J Mol Cell Cardiol 2007; 42: 1026-1035.

30. Zhang HB, Li RC, Xu M, Xu SM, Lai YS, Wu HD et al. Ultrastructural uncoupling between T-tubules and sarcoplasmic reticulum in human heart failure. Cardiovasc Res 2013; 98 : 269-276.

31. Margolis RL, O'Hearn E, Rosenblatt A, Willour V, Holmes SE, Franz ML et al. A disorder similar to Huntington's disease is associated with a novel CAG repeat expansion. Ann Neurol 2001; 50: 373-380.

32. Holmes SE, O'Hearn E, Rosenblatt A, Callahan C, Hwang HS, Ingersoll-Ashworth RG et al. A repeat expansion in the gene encoding junctophilin-3 is associated with Huntington disease-like 2. Nat Genet 2001; 29: 377-378.

33. Guo A, Zhang X, lyer VR, Chen B, Zhang C, Kutschke WJ et al. Overexpression of junctophilin-2 does not enhance baseline function but attenuates heart failure development after cardiac stress. Proc Natl Acad Sci U S A 2014; 111: 12240-12245.

34. Yi M, Weaver D, Eisner V, Varnai P, Hunyady L, Ma J et al. Switch from ER-mitochondrial to SR-mitochondrial calcium coupling during muscle differentiation. Cell Calcium 2012; 52 : 355-365.

35. de Brito OM, Scorrano L. Mitofusin 2 tethers endoplasmic reticulum to mitochondria. Nature 2008; 456: 605-610.

36. Iwabu M, Yamauchi T, Okada-Iwabu M, Sato K, Nakagawa T, Funata M et al. Adiponectin and AdipoR1 regulate PGC-1alpha and mitochondria by $\mathrm{Ca}(2+)$ and AMPK/SIRT1. Nature 2010; 464: 1313-1319.
37. Soriano FX, Liesa M, Bach D, Chan DC, Palacin M, Zorzano A. Evidence for a mitochondrial regulatory pathway defined by peroxisome proliferator-activated receptor-gamma coactivator-1 alpha, estrogen-related receptor-alpha, and mitofusin 2. Diabetes 2006; 55 : 1783-1791.

38. Sorianello E, Soriano FX, Fernandez-Pascual S, Sancho A, Naon D, Vila-Caballer M et al. The promoter activity of human Mfn2 depends on Sp1 in vascular smooth muscle cells. Cardiovasc Res 2012; 94: 38-47.

39. Ngoh GA, Papanicolaou KN, Walsh K. Loss of mitofusin 2 promotes endoplasmic reticulum stress. J Biol Chem 2012; 287: 20321-20332.

40. de Brito OM, Scorrano L. An intimate liaison: spatial organization of the endoplasmic reticulum-mitochondria relationship. Embo J 2010; 29: 2715-2723.

41. Augustine GJ, Neher E. Calcium requirements for secretion in bovine chromaffin cells. J Physiol 1992; 450: 247-271.

42. Sebastian D, Hernandez-Alvarez Ml, Segales J, Sorianello E, Munoz JP, Sala D et al. Mitofusin 2 (Mfn2) links mitochondrial and endoplasmic reticulum function with insulin signaling and is essential for normal glucose homeostasis. Proc Natl Acad Sci U S A 2012; 109: 5523-5528.

43. Parekh A. Calcium signalling: mitofusins promote interorganellar crosstalk. Curr Biol 2009; 19: R200-R203.

44. Hawley JA, Hargreaves M, Joyner MJ, Zierath JR. Integrative biology of exercise. Cell 2014; 159: 738-749

45. Bianchi K, Vandecasteele G, Carli C, Romagnoli A, Szabadkai G, Rizzuto R. Regulation of $\mathrm{Ca} 2+$ signalling and $\mathrm{Ca} 2+-$ mediated cell death by the transcriptional coactivator PGC-1alpha. Cell Death Differ 2006; 13: 586-596.

46. Agudelo LZ, Femenia T, Orhan F, Porsmyr-Palmertz M, Goiny M, Martinez-Redondo V et al. Skeletal muscle PGC-1alpha1 modulates kynurenine metabolism and mediates resilience to stress-induced depression. Cell 2014; 159: 33-45.

47. Li L, Li T, Zhang Y, Pan Z, Wu B, Huang $X$ et al. Peroxisome proliferator-activated receptorbeta/delta activation is essential for modulating $\mathrm{p}$-Fox01/Fox01 status in functional insulin-positive cell differentiation. Cell Death Dis 2015; 6: e1715.

48. Li DS, Yuan YH, Tu HJ, Liang QL, Dai LJ. A protocol for islet isolation from mouse pancreas. Nat Protoc 2009; 4: 1649-1652.

49. Hedeskov CJ, Capito K. The effect of starvation on insulin secretion and glucose metabolism in mouse pancreatic islets. Biochem J 1974; 140: 423-433.

(c) Cell Death and Disease is an open-access journal published by Nature Publishing Group. This work is

licensed under a Creative Commons Attribution 4.0 International License. The images or other third party material in this article are included in the article's Creative Commons license, unless indicated otherwise in the credit line; if the material is not included under the Creative Commons license, users will need to obtain permission from the license holder to reproduce the material. To view a copy of this license, visit http://creativecommons.org/licenses/by/4.0/

(C) The Author(s) 2016

Supplementary Information accompanies this paper on Cell Death and Disease website (http://www.nature.com/cddis). 